\title{
Experimental Investigation of the Influence of Chlorhexidine Gel on the Implant-Abutment- Connection
}

\author{
Vasilios Alevizakos ${ }^{1 *}$, Marcus Schiller ${ }^{3 *}$, Ahmed Othman², Lisa Mandlbauer ${ }^{2}$ and Constantin Von See ${ }^{2}$ \\ ${ }^{1}$ Danube Private University, Center for Digital Technologies in Dentistry and CAD/CAM, Austria \\ ${ }^{2}$ Danube Private University, DPU Dental Clinic, Austria \\ ${ }^{3}$ Medical School Hannover, Department of Oral and Maxillofacial Surgery, Germany
}

\begin{abstract}
Background: The aim of this study was to determine the effect of chlorhexidine gel on removal torque of abutment prosthesis screws in vitro.

Methods: 60 implants (BEGO Semados ® S/RI 4.1, BEGO Implant Systems GmbH \& Co. KG, Bremen, Germany) were embedded in acrylic resin for study set-up. The abutments (S/RI 4.1 SUB-TEC WI, BEGO Implant Systems GmbH \& Co. KG, Bremen, Germany) were fixed with prothesis screws with $25 \mathrm{Ncm}$ on the implants and were loaded for 10.000 cycles with $250 \mathrm{~N}$ in a static material testing machine. The implemented study consisted of three groups $(n=20)$. Group 1 (control group) were loaded under dry conditions. Group 2 was filled with a saliva substitute only (Sialin-Sigma solution, Sigmapharm Arzneimittel GmbH, Vienna, Austria), group 3 was filled with a saliva substitute and additional with chlorhexidine gel (Chlorhexamed 1\% GEL, GlaxoSmithKline Consumer Healthcare GmbH \& Co. KG, München, Germany). Statistical analysis was performed using ANOVA (significance level $p<0.05$ ).
\end{abstract}

Results: The control group showed the smallest range of removal torque (19.85 $\mathrm{Ncm} \pm 1.42 \mathrm{Ncm}$ ) while group 2 showed 20.32 $\mathrm{Ncm} \pm 2.61 \mathrm{Ncm}$ and in group 3 was $19.74 \mathrm{Ncm} \pm 2.96 \mathrm{Ncm}$. No significant differences between the three groups were evaluated

Conclusion: Within the limits of this in-vitro study, it can be concluded that the application of chlorhexidine gel did not show any significant effect on the removal torque on abutment screws after loading.

KEYWORDS: Implant dentistry; Chlorhexidine gel; Bacterial effect

\section{INTRODUCTION}

Due to the increasing desire of patients for fixed dentures, the improvement of the hold of the prosthesis and the aim of avoiding the preparation of natural teeth and in worst case healthy teeth as a support element, implant placement is considered as an advantageous alternative to conventional dentures [1]. The prosthetic interface between the implant and the restoration is the abutment, on which the prosthetic restoration can be screwed on or cemented. The abutments are screwed into the implants and usually surrounded by the soft tissue [2]. As a result, they are permanently in contact with the bacteria-inhabited oral cavity. Zipprich et al. [3] investigated the effect of the bacterial micro leakage in implant systems with planar and conical implant abutment compounds before and after cyclic loading. It was found that conical implant abutment compounds had a better seal compared to planar implant abutment compounds, which showed an increased micro leakage after cyclic loading. Zipprich et al. [3] identified the micro leakage in the implant abutment compound

\begin{tabular}{|c|c|}
\hline \multirow{2}{*}{ 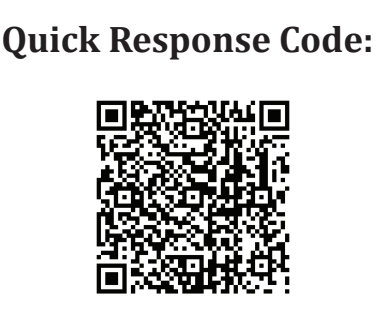 } & $\begin{array}{l}\text { Address for correspondence: Vasilios Alevizakos, Marcus Schiller, Department of } \\
\text { Oral and Maxillofacial Surgery, Germany }\end{array}$ \\
\hline & $\begin{array}{l}\text { Received: February 19, } 2021 \quad \text { Published: March 01, } 2021 \\
\text { How to cite this article: Vasilios A, Marcus S, Ahmed O, Lisa M, Constantin VS. Experimental } \\
\text { Investigation of the Influence of Chlorhexidine Gel on the Implant-Abutment-Connection. 2021- } \\
\text { 3(2) OAJBS.ID.000260. DOI: } 10.38125 / \text { OAJBS.000260 }\end{array}$ \\
\hline
\end{tabular}


as a link to micro-movement, technical failure, and crestal bone resorption [4].

Currently, only a few methods are known for the prevention of pathological changes around implants caused by bacteria. Regarding this finding, reference is made in this study to the antibacterial effect of chlorhexidine [5-8]. Recent studies showed the positive effect of chlorhexidine on the healing process of implants. Chlorhexidine is a biguanide derivative and belongs to the surface-active ammonium compounds with unspecific bactericidal effects [9]. An application of chlorhexidine gel between the implant and the abutment could have an antibacterial effect $[10,11]$.

The influence of lubricants leads to marked differences in the holding compound between screwed connections in industrial applications. Since the lubrication of a screw reduces the frictional resistance and thus leads to easier screwing, it is conceivable that the change in the preload results in an increased strength of the screw connection [9]. Binon and McHugh concluded that there was an increased resistance to screw loss due to a reduction in rotational clearance [12].

The increasing treatment of single tooth gaps by implant supported restorations also in the posterior tooth area results in increased mechanical stress on the implant-abutment connection, which often becomes the mechanical weak point [13].

Steinebrunner et al. [14] described the implant-abutment connection as important because it is responsible for leakage caused by micro-movements, loosening of the screws and screw fractures. The aim of this study was to investigate the effect of chlorhexidine gel on the implant-abutment connection.

\section{MATERIAL AND METHOD}

\section{Preliminary Tests}

For preliminary tests, 26 implants (BEGO Semados® S/RI 4.1, BEGO Implant Systems GmbH \& Co. KG, Bremen, Germany) of different lengths were embedded in cold-curing polymer (Combipress N/LM, Merz Dental, Lütjenburg, Germany) in the crown nuts (DIN 935 M15). The crown nuts were fastened in the universal testing machine (Zwick/Roell Z010 TN, Zwick GmbH \& Co. KG, Ulm, Germany).

The abutment screws were tightened with $25 \mathrm{Ncm}$. The speed in the setting cycle was limited to $250 \mathrm{~N}$ and the first 13 preliminary tests were limited to 100 cycles. The load of $250 \mathrm{~N}$ was chosen because this value is within the physiological range of the load on the molar region [3].

In the preliminary tests, it was found that the removal torque was reduced by a maximum of $5 \mathrm{Ncm}$, regardless of whether the abutment screw was dry, wetted with saliva substitute or CHX gel during screwing. Subsequently, the idea emerged of a test carrier made of steel, which can be filled with saliva substitute so that the implant abutment compound could be covered in saliva substitute. This was intended to create similar conditions to oral cavity.

\section{Trial Setup}

For the production of the test objects, 60 implants with a diameter of $4.1 \mathrm{~mm}$ and an internal implant-abutment connection (S/RI 4.1, BEGO Implant Systems GmbH \& Co. KG, Bremen, Germany) were embedded in crown nuts (DIN 935 M15) with a cold-curing polymer (Combipress N/LM, Merz Dental, Lütjenburg, Germany) The bottom of the crown nuts was sealed with a kneading silicone to prevent the cold-curing polymer flowing away from the crown nuts. In order to provide a vertical embedding of the implants, they were fixed in a drill chuck (Figure 1).

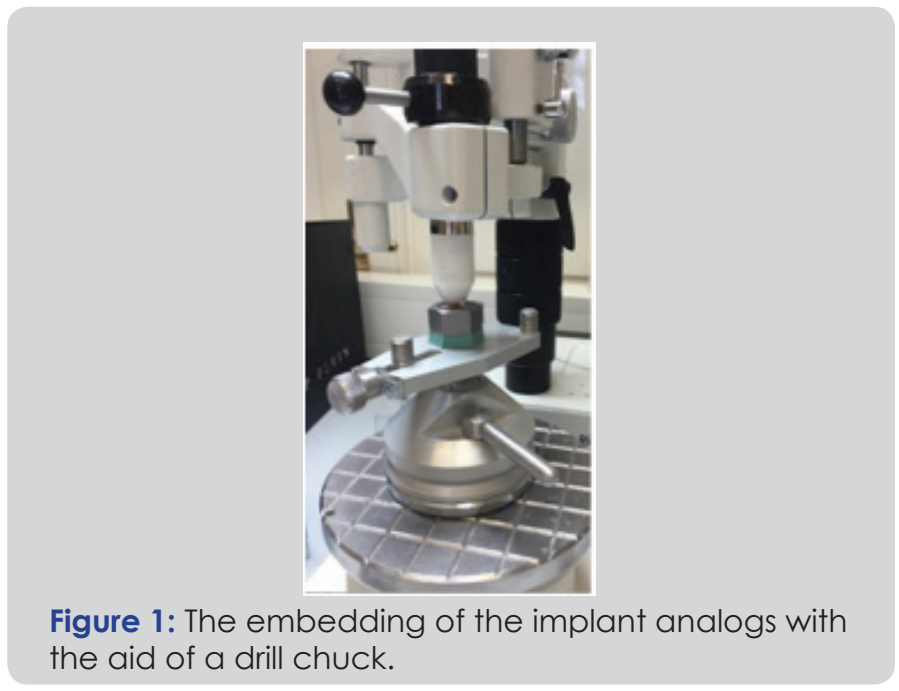

Then the fixed implants were lowered into the cold-curing polymer, which was previously filled into the crown nut. The polymer was finally cured in a pressure pot. After all implants were embedded in the crown nuts, the abutments (S/RI 4.1 SUB-TEC WI, BEGO Implant Systems GmbH \& Co. KG, Bremen, Germany) were screwed manually into the embedded implants with $25 \mathrm{Ncm}$ using a calibrated torque-measuring device (HTGS-10N, PCE Deutschland $\mathrm{GmbH}$, Meschede, Germany). The torque-measuring device was clamped in a drill stand in order to ensure the abutment screw to be screwed-in vertically (Figure 2).

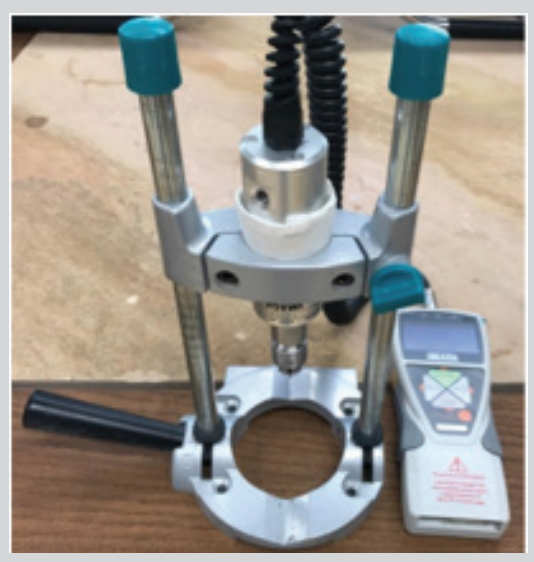

Figure 2: The torque-measuring device clamped in the drill stand.

In order to create oral cavity-like conditions, a tub made of steel was manufactured to hold liquids. Each prepared crown nut was positioned inside the metallic tub, which was clamped inside the test carrier of the testing machine. The edges of the tub were higher than the crown nut, so that the abutments could be totally covered in saliva substitute (Sialin-Sigma solution, Sigmapharm Arzneimittel $\mathrm{GmbH}$, Vienna, Austria). Sialin-Sigma is used to moisturize the oral and pharyngeal mucosa.

The mechanical behavior of the implant-abutment-nut-tub compound was evaluated under simulated loading conditions using a static materials testing machine (Zwick/Roell Z010 TN, Zwick GmbH \& Co. KG, Ulm, Germany) (Figure 3). 
Before the test procedure was started, the testing machine was set in the testing software (testXpert II, Zwick GmbH \& Co. KG, Ulm, Germany). For each specimen the load point was $250 \mathrm{~N}$, the speed of the cycles $50 \mathrm{~mm} / \mathrm{min}$ and the total number of cycles 10,000 .
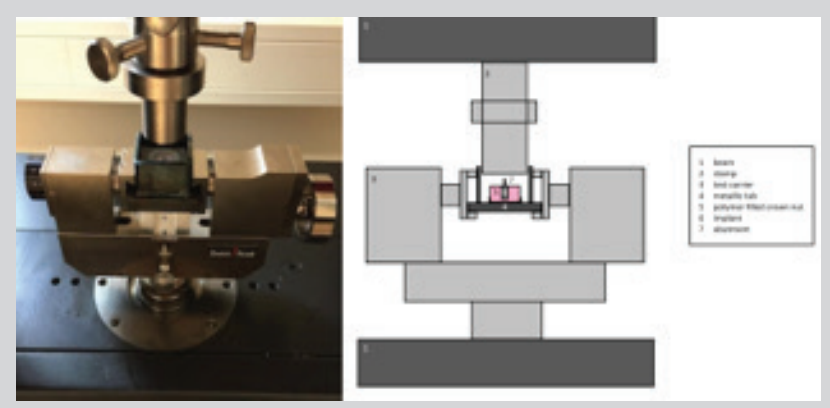

Figure 3: The metallic tub filled with saliva substitute and clamped inside the test carrier of the testing machine.

\section{Trial Implementation}

The 60 embedded implants were separated in three group of the same size. In group 1 (G1), the control group, the test was performed under dry conditions. In group 2 (G2), Sialin-Sigma solution (Sigmapharm Arzneimittel GmbH, Vienna, Austria) was added to the implant abutment compound. In group 3 (G3), the abutments were wetted with chlorhexidine gel (Chlorhexamed 1\% GEL, GlaxoSmithKline Consumer Healthcare GmbH \& Co. KG, München, Germany), then screwed into the implants and the test was performed under oral cavity-like conditions by applying SialinSigma solution (Sigmapharm Arzneimittel GmbH, Vienna, Austria). After the testing procedure was finished, the removal torque was determined by means of the hex wrench fixed in the torque meter.

\section{RESULTS}

A total of 60 implants were used to compare three different experimental setups: dry, with saline substitute and with chlorhexidine gel only and chlorhexidine gel together with saline substitute. Due to problems during the testing procedure within two groups, two testing trials could not be included into the evaluation. So, a total of 58 measured values were obtained and analyzed (Figure 4,5). The control group showed a mean value of removal torque of $19.85 \mathrm{Ncm} \pm 1.42 \mathrm{Ncm}$. Compared to that, group 2 and 3 showed greater values. The removal torque in group 2 was $20.32 \mathrm{Ncm} \pm 2.61 \mathrm{Ncm}$ and in group 3 was $19.74 \mathrm{Ncm} \pm 2.96 \mathrm{Ncm}$. Not only were the mean values different but also the range of values (Figure 4,5). In group 1 the values ranged from $18 \mathrm{Ncm}$ to $23 \mathrm{Ncm}$, in group 2 from $14 \mathrm{Ncm}$ to $24 \mathrm{Ncm}$ and in group 3 from $12 \mathrm{Ncm}$ to $23 \mathrm{Ncm}$.

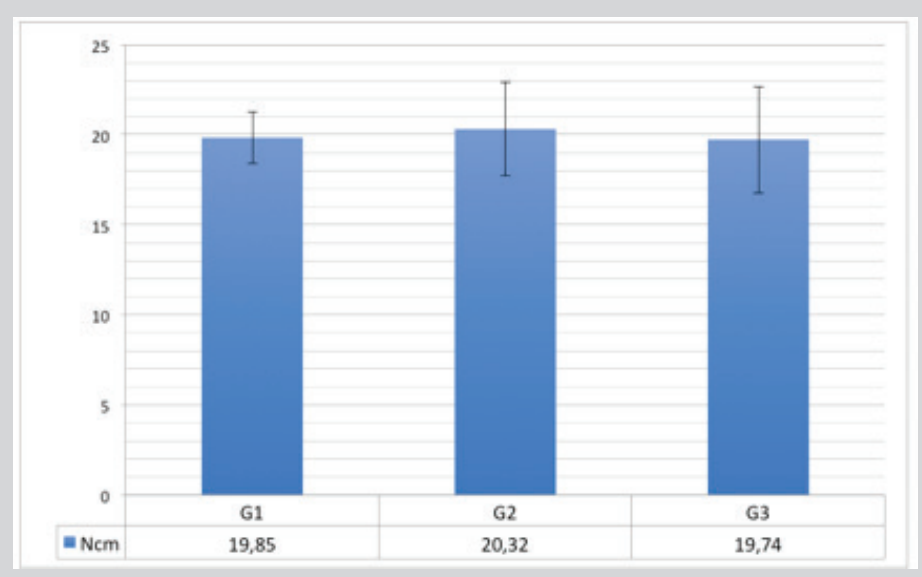

Figure 4: Mean values of the applied removal torque.

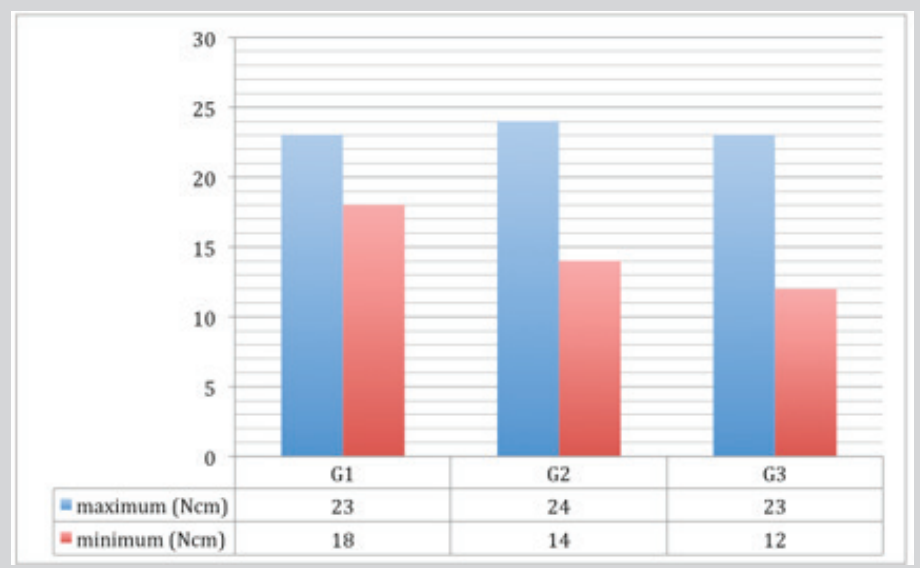

Figure 5: Range of values. 


\section{Statistical Analysis}

The Lilliefors test and the Mann-Whitney U test were used to evaluate the results. When the values were isolated, no significant effects could be determined. The Lilliefors test showed a $p$-value $<$ 0.001 for the series of tests in group 3 , and for group $2, p<0.001$ and for the control group $p=0.009$ were calculated. The result of the Wilcoxon test for the comparison of group 2 and 3 was $p$ $=0.779$. In the comparison of the control group with group 3 the $p$-value was 0.636 . For the comparison of the control group with group 2, the Wilcoxon test showed a $p$-value of 0.317 . All the three differences were not a statistically significant $(p>0.05)$ (Figure 6).

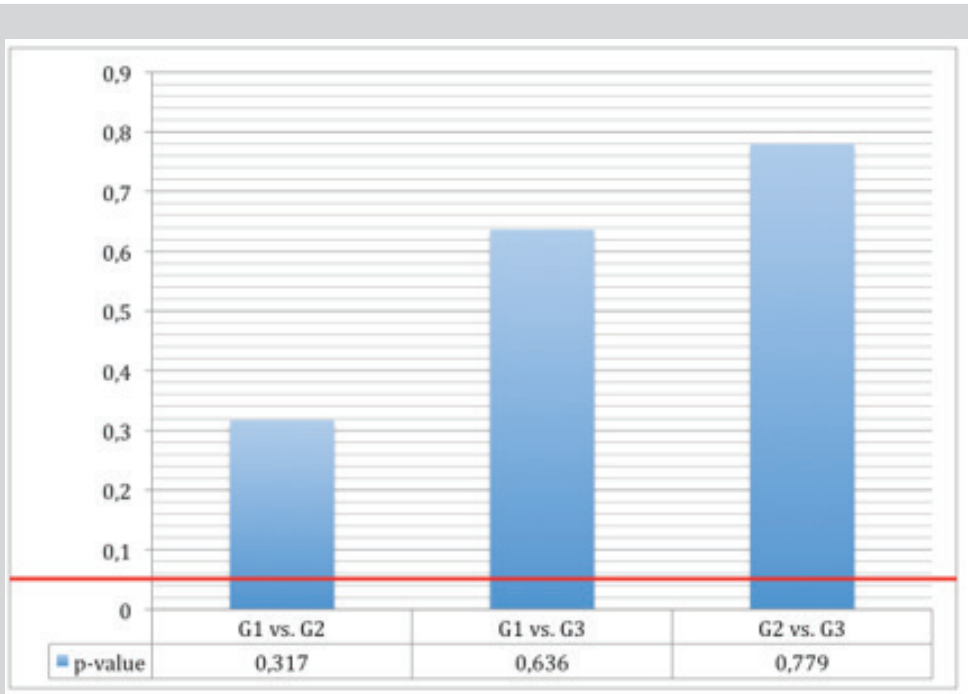

Figure 6: $p$-values of the Wilcoxon-test; $p>0.05$.

\section{DISCUSSION}

\section{Method}

Changes of the removal torque occurred when the abutments were screwed in with CHX gel and loaded with 10,000 cycles in the test carrier filled with saliva substitute. The test setup was consisted of three different examination groups (dry, Sialin-Sigma, Sialin-Sigma + CHX-gel), in which the abutments were all loaded with $250 \mathrm{~N}$ for 10,000 cycles in the testing machine (Zwick/Roell Z010 TN, Zwick GmbH \& Co. KG, Ulm, Germany). By embedding the implants in cold-curing polymer (Combipress N/LM, Merz Dental, Lütjenburg, Germany) with the aid of a drill chuck, it was tried to place them as perpendicularly and reproducibly as possible. In order to achieve a perpendicular rotation of the abutment screws, the torque-measuring device with the hex wrench (Ratchet, BEGO Implant Systems, Bremen, Germany) fixed therein was clamped in a drill stand to turn the abutment in and out.

The abutments were loaded vertically. The setting of the tests was edited using the test software testXpert II (Zwick GmbH \& Co. KG, Ulm, Germany). Due to technical problems, two tests could not be evaluated because the test machine aborted several times. The technical problem was the result of a loosened screw of the protective door. Within group 3, an abutment screw clamped with CHX gel using the hex wrench. One point of criticism of this experimental design was that all implants were embedded vertically in prosthesis articulation and the abutments were loaded perpendicularly without a prosthetic restoration by a flat plate. In comparison to other studies, such as the in vitro study by Zipprich et al. in which titanium balls of $4 \mathrm{~mm}$ diameter were cemented on the abutments [3].

In the study by Koutouzis et al. [15] the dynamic load was performed by a masticatory simulator and transferred to the abutments at a $30^{\circ}$-angle through a stainless-steel stylus. The angle of $30^{\circ}$ was intended to reflect the cusp inclination of the molars and thus transfer the stress as similar as possible to force transmission in the oral cavity. Regarding the study design, it is also to be criticized that only implant-abutment connection with an internal hexagonal compound was tested in the examination groups.

The results showed that the removal torque is always less than the insertion torque. In the two-group comparison using the MannWhitney $\mathrm{U}$ test, the results were not significant. To illustrate the results, the mean values of the three study groups were determined (Figure 4) The control group had the smallest range of values. The maximum-value in this group was $23 \mathrm{Ncm}$ and the minimum-value $18 \mathrm{Ncm}$. The maximum-value of group 2 was $24 \mathrm{Ncm}$ and of group $323 \mathrm{Ncm}$. The minimum-value of group 2 and 3 were $14 \mathrm{Ncm}$ and $12 \mathrm{Ncm}$, respectively. Butignon et al. [16] and Khraisat et al. [17] showed in their in-vitro study that the removal torque significantly decreased after cyclic loading. By scanning with an electron microscope, structural changes of the abutments, such as wear, and structural losses were compared before and after the cyclic loading [16].

The flattening of microscopic unevenness leaded to a circumvention of the friction. The relaxation of the contact surfaces was also described as a "settling-effect" and resulted in a reduction of the preload, since part of the applied torque was used to circumvent the friction $[13,18]$.

Due to the great influence of the implant-abutment connection on the long-term success of implants, the clinical importance of this potential weak spot is high. The unavoidable micro leakage between the implant and the abutment allows penetration of periodontalpathogenic bacteria, which could lead to an inflammatory reaction of the surrounding tissue and in worst-case cause the loss of the implant [19]. Ghannad et al. [20] showed in their study that the application of 1\% CHX gel into the abutment screw hole in morsetaper implant systems leads to a significant reduction of bacteria over a period of 110 days. 


\section{CONCLUSION}

Based on the results of the study by Ghannad the authors recommended that the prevention of bacterial colonization of the implant-abutment connection should be a part of the treatment standard in implantology. The authors recommended, however, not only the application of 1\% CHX gel during the implant placement, but also after every abutment insertion. Due to lack of significance during comparison of the groups in the present study, it could be assumed that the application CHX gel has no negative influence on the strength of tested implant-abutment connection. Future studies should determine the long-term effect of CHX gel on different implant-abutment connections.

\section{REFERENCES}

1. Gutwald R, Gellrich NC, Schmelzeisen R (2010) Einführung in die zahnärztliche chirurgie and implantologie. Deutscher Zahnärzte Verlag 634.

2. Strub JR, Kern M, Türp JC, Witkowski S, Heydecke G, et al. (2011) Curriculum Prothetik Band III Quintessenz Verlag.

3. Zipprich H, Sven M, Rim H, Hans CL (2016) A New experimental design for bacterial microleakage investigation at the implant-abutment interface: An in vitro study. Int J Oral Maxillofac Implants 31(1) 37-44.

4. Zipprich H (2007) Erfassung, ursachen und folgen von mikrobewegungen am implantat-abutment-interface. Implantologie 15: 31-46.

5. Azimi M, Leila J, Shahram M, Ezatolah G, Naser B, et al. (2016) Antimicrobial effects of chlorhexidine, matrica drop mouthwash (chamomile extract), and normal saline on hospitalized patients with endotracheal tubes. Iran J Nurs Midwifery Res 21(5): 458-463.

6. Grenier D (1993) Reduction of proteolytic degradation by chlorhexidine. J Dent Res 72(3): 630-633.

7. De SF, Francetti L, Corbella S, Taschieri S, Del MF, et al. (2013) Topical application of $1 \%$ chlorhexidine gel versus $0.2 \%$ mouthwash in the treatment of peri-implant mucositis. An observational study. Int J Dent Hyg 11(1): 41-47.

8. Supranoto SC, DE Slot, M Addy, Van GA (2015) The effect of chlorhexidine dentifrice or gel versus chlorhexidine mouthwash on plaque, gingivitis, bleeding and tooth discoloration: a systematic review. Int J Dent Hyg 13(2): 83-92.
9. Krishnan V, Tony TC, Sabu I (2014) Management of abutment screw loosening: review of literature and report of a case. J Indian Prosthodont Soc 14(3): 208-214

10. Koutouzis T, Gadalla H, Lundgren T (2016) Bacterial colonization of the implant-abutment interface (IAI) of dental implants with a sloped marginal design: An in-vitro study. Clin Implant Dent Relat Res 18(1): 161-167.

11. Paolantonio M, Giuseppe P, Simonetta DE, Filippo G, Giovanni C, et al. (2008) Internal decontamination of dental implants: an in vivo randomized microbiologic 6-month trial on the effects of a chlorhexidine gel. J Periodontol 79(8): 1419-1425.

12.Binon PP, Mc Hugh MJ (1996) The effect of eliminating implant/ abutment rotational misfit on screw joint stability. Int J Prosthodont 9(6): 511-519.

13. Ki Seong K, Jung SH, Young JL (2014) Settling of abutments into implants and changes in removal torque in five different implant-abutment connections. part 1: cyclic loading. Int J Oral Maxillofac Implants 29(5): 1079-1084.

14. Steinebrunner L, Stefan W, Klaus B, Matthias K (2005) In vitro evaluation of bacterial leakage along the implant-abutment interface of different implant systems. Int J Oral Maxillofac Implants 20(6): 875-881.

15. Koutouzis T, Hana G, Zachary K, Amelsaad E, Jörg N, et al. (2015) The role of chlorhexidine on endotoxin penetration to the implant-abutment interface (IAI). Clin Implant Dent Relat Res 17(3): 476-482.

16. Butignon LE, Mariana De, Rodrigo PP, Joao NAF (2013) Influence of three types of abutments on preload values before and after cyclic loading with structural analysis by scanning electron microscopy. Int J Oral Maxillofac Implants 28(3): e161-170.

17. Khraisat A, Akihiko H, Shuichi N, Osamu M (2004) Effect of lateral cyclic loading on abutment screw loosening of an external hexagon implant system. J Prosthet Dent 91(4): 326-334.

18. Hung WL (2015) The Effect of contamination of implant screws on reverse torque. Int J Oral Maxillofacial Implants 30(5): 1054.

19. Podhorsky A, Stefanie B, Peter R, Philipp S, Eugen D, et al. (2016) Transfer of bacteria into the internal cavity of dental implants after application of disinfectant or sealant agents in vitro. Int J Oral Maxillofac Implants 31(3): 563-570

20. Ghannad F, Lubna TA, Colin BW, Ya S, Markus H, et al. (2015) Intraoperative application of chlorhexidine gel reduces bacterial counts in internal implant cavity. Eur J Oral Sci 123(6): 425-431. 